\title{
Study of Optimum Cutting While Lathing Carbonate Steel VCN-150 Uses a Layered Carbide Chisel PVD on Dry and Wet Condition
}

\author{
Muksin R. Harahap, Ahmad Bakhori, Suhardi Napid, Muhammad Rafiq Yanhar, Abdurrozzaq Hasibuan \\ Faculty of Engineering, Universitas Islam Sumatera Utara, Medan, Indonesia \\ *Corresponding author E-mail: muksin.harahap@ft.uisu.ac.id
}

\begin{abstract}
To improve the productivity of this machining perhaps it may be recommended in a dry cutting but a dry cutting is recognized very sensitive to a high temperature. In this case, in order to overcome is perhaps required by using a tool carbide either in layers or without any layers whereby each layer has certain superior. There was conducted an experiment to have an optimum cutting on a carbon steel VCN150 using a layers tool carbide and Respond Surface Method (RSM) with a CCD operation. The result of study recommended that condition optimum cutting shall be achieved (When cutting $t_{c}$ ) on a medium machining refers to ISO 3685 and medium surface roughness $\left(\mathrm{R}_{\mathrm{a}}\right)$ ISO 1320. Statistically, there is no found significant difference between a dry and wet cutting on optimum dry condition.
\end{abstract}

Keywords: Dry Cutting, Optimum Cutting, Surface, Roughness, Flank Wear

\section{Introduction}

It is mostly in Medan and surroundings area the Small and Middle scale industries (SMI) on machining found that cutting on carbon steel, gray cast iron and non ferro and chisels there is used a High Speed Steel (HSS), proudly as in manufactured is able to competed with similar products. Unfortunately, the industries are facing a lower productivity as main problem.

In order to overcome the causes of lower productivity as above, it is highly required solution with improvements as in generally called machine-ability up. In order to improve machine-ability of carbon steel as material many used by SMIs in Medan, several researchers reported already the methods to improve a machineable of the material[1], [2].

Wassila's publication reported that parameters of cutting such as speed of cutting (V), feed (f), and depth of cutting (a) can be more optimum to shorten time duration (production) and to have maximum productivity.

Noordin [3] reported that the speed of cutting is very influential factor to $\mathrm{R}_{\mathrm{a}}$ that analyzed adopting analysis of variance (anoval), So, a dry cutting has highly potential to replace the wet cutting. Haroen [4] reported that packaging surface of product is highly influenced by condition of cutting, worn chisel with lubricated cutting or not while cutting[5]-[7]. Therefore, no fluid machining (dry cutting) has potency to replace the machining with liquid (wet cutting).

A dry cutting while cutting the carbon steel will be influenced by a rapid and highly rising of temperature cutting that able to damage chisel soon[3], [8], [9]. One of solutions to overcome the problems on the dry cutting is recommended using a chisel as designed capable to work in a highly temperature of cutting as layered carbide or not layer [9] [8] reported that coating carbide chisel is capable to improve the hardness and toughness of chisel that it should reduce friction and worn out chisel[10]-[14].

In order to have optimum cutting is there used Respond Surface Method (RSM) since in this method the data (population) required can be limited possible saving time and cost as it has already done [3]. The objective of this study are:

a. To obtain an optimum cutting condition on carbon steel lathing VCN-150 using a layer carbide chisel with Respond Surface Method (RSM).

b. To compare performance of dry cutting and wet cutting while working on roughness

\section{Methodology}

The material in this study used carbon steel VCN-150 in rounded geometry with mechanical and chemical properties as in table 1.

Table 1: Mechanical Property of Carbon Steel VCN-150

\begin{tabular}{|c|l|l|}
\hline No & \multicolumn{1}{|c|}{ Description } & \multicolumn{1}{c|}{ Volume } \\
\hline 1. & Tensile strength ultimate & $584.23 \mathrm{Mpa}$ \\
\hline 2. & Tensile strength yield & $373.65 \mathrm{Mpa}$ \\
\hline 3. & Elongation at break & $49.6 \%$ \\
\hline 4. & Vickers hardness & $184.8 \mathrm{VHN}$ \\
\hline 5. & Poisson's ratio & 0.29 \\
\hline 6. & Shear modulus & $80 \mathrm{Gpa}$ \\
\hline 7. & Density & $7.85 \mathrm{~g} / \mathrm{cc}$ \\
\hline
\end{tabular}

Table 2: Chemical Composition of VCN-150

\begin{tabular}{|c|c|c|c|c|c|}
\hline $\mathrm{C} \%$ & $\mathrm{Mn} \%$ & $\mathrm{P} \%$ & $\mathrm{Cr} \%$ & $\mathrm{Si} \%$ & $\mathrm{Ni} \%$ \\
\hline $0.43 \div 0.5$ & $0.6 \div 0.9$ & 0.01 & $0,03 \div 1.5$ & $0.24 \div 0.3$ & $0.1 \div 1.5$ \\
\hline
\end{tabular}


In analyzing the data, this study adopted Respond Survey Method (RSM), beside it is fitting to use of taking data destructively done, but also very applicable to have an optimum price in the study, where it may comprised data input more than two, and its stationary point can be determined yet. The testing has been done to obtain specimen behavior $R_{a}$ on the machining process of dry and wet cutting. In the testing, it has been chosen machining process with lathing machining $\mathrm{CNC}$ having a manufacturing standard EMCOTURN-242 and tool holder PTGNR.2020-K16T. The chisel used such as insert type of standard ISO M-15 TCGT 110204RK Seri CT5015 two layers WC+Co/TiAIN+TiN formed triangle $60^{\circ}$ with the cutting data as below.

Table 3: The Cutting Data of Chisel

\begin{tabular}{|c|l|c|}
\hline \multicolumn{3}{|c|}{ Table 3: The Cutting Data of Chisel } \\
\hline No. & \multicolumn{1}{|c|}{ Details } & Unit \\
\hline 1. & Angle Radius ( $\mathrm{r}_{\mathrm{c}}$ ) & $0.3 \mathrm{~mm}$ \\
2. & Depth of Cutting (a) & $0.4 \div 5.0 \mathrm{~mm}$ \\
3. & Clear-cut (f) & $0.1 \div 0.3 \mathrm{~mm} / \mathrm{rev}$ \\
4. & Speed of cutting (V) & Max. $480 \mathrm{~m} / \mathrm{min}$ \\
\hline
\end{tabular}

Still, measure tool need to use such as:

a. Measuring tool surface roughness

b. Measuring tool to a product dimension

c. Measuring tool tachometer

d. Measuring tool stop watch.

e. Measuring tool to a wear instrument (Loeb)

This study shall be done in stages, assumed that product of machining and measuring of specimen shall be made in table to be seen clearly the correlation inter variable to simplify a further process, started in:

1. Pre-study is to get $R_{a}$ and $t_{c}$ values in a minimum and maximum cutting condition of carbonate steel VCN-150 bases to ISO 3685

2. Entry the data of pre-study result into Minitab software with central composite design (CCD) operation with $\alpha=1$

3. Make planning to optimal $\mathrm{V}$, f and a by treatment value of $\mathrm{R}_{\mathrm{a}}$ and $\mathrm{t}_{\mathrm{a}}$

4. To have respond optimize by input condition of cutting result treatment

5. Make calculation using two-order equation to $R_{a}$ and $t_{c}$ in order to have mathematics equation model

6. Determine a dry optimum cutting condition on $\mathrm{R}_{\mathrm{a}}(1.6 \div 6.3$ $\mu \mathrm{m})$ and $\mathrm{t}_{\mathrm{c}}(10 \div 15 \mathrm{men})$ on $\mathrm{V}_{\mathrm{B}} 0.3 \mathrm{~mm}$ to medium machining bases the result of calculation.

7. Make cutting and re-measuring on optimum cutting condition either dry or wet.

Pre-study cutting is done aimed at getting a minimum cutting condition (lowest limit) and maximum cutting condition (highest limit) able to gain by chisel refers to recommendation Tiziloque, (2003) on a medium work material carbonate steel with hardness 184.8 VHN and the results as Table 4 below.

Table 4: Condition of Pre-Study Cutting

\begin{tabular}{|c|c|c|c|c|c|c|}
\hline No & $\mathrm{V}$ & $\mathrm{f}$ & $\mathrm{a}$ & $\mathrm{V}_{\mathrm{B}}$ & $\mathrm{t}_{\mathrm{c}}$ & $\mathrm{R}_{\mathrm{a}}$ \\
\hline 1 & 300 & 0.1 & 2.5 & 0,3 & 25.2 & 2.3 \\
\hline 2 & 450 & 0.25 & 3.5 & 0.3 & 5.6 & 12.6 \\
\hline
\end{tabular}

It has been conducted a treatment to optimal condition of cutting $\mathrm{V}$ (speed of cutting), and $\mathrm{f}$ (clear-cut) and a (depth of cutting) on value ranged $\mathrm{Ra}$ between $2.3 \div 12.6 \mu \mathrm{m}$ and $\mathrm{t}_{\mathrm{c}}$ between $5.6 \div 25.2$ men. The purpose is to have respond surface regression $\left(R_{a}\right)$ and cutting time regression ( $t_{c}$ versus speed of cutting $(V)$, clear-cut $(f)$ and depth of cutting (a) until find a probability gain rate $5 \%$.

\section{Results and Discussion}

The cutting condition as resulted in pre-study then, analyzed using a Respond Surface Method (RSM). This analysis is done with aided soft-ware Minitab-16 obtained from www/minitab.com/downloads freely, fully-functional version of Minitab-16 for 30-day trial (Minitab Inc, 2016). The results of pre-study as above, further analyzed using a software Minitab 14 with central operation CCD factor $=3$, replicate $=1$, base run $=20$, total run $=20$, total block $=1$ and $\alpha=1$. The data result of cutting in pre-study is then input into software Minitab-16 and the result as Figure 1. It can be seen on Figure 1 that correlation between $R_{a}$ and $t_{c}$ on a lower surface roughness rate (fine) required a longer time of cutting and vice versa. Alike condition indicated that there is an influencing each other between cutting condition variable over $\mathrm{R}_{\mathrm{a}}$ and $\mathrm{t}_{\mathrm{c}}$ of machining.

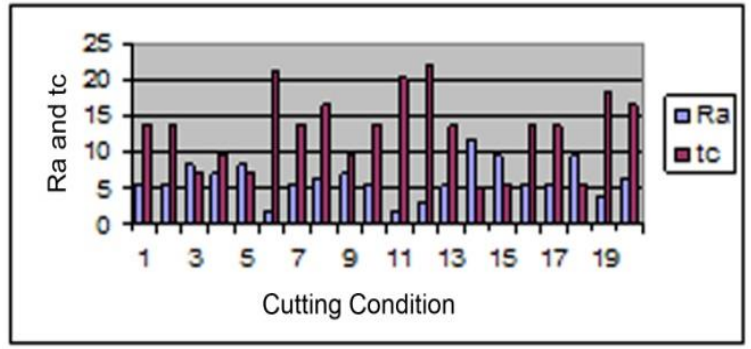

Figure 1: Graphic Treatment $\mathrm{Ra}$ and $\mathrm{t}_{\mathrm{c}}$

This alike condition indicated that limit range of cutting condition as observed, is not sufficient although the cutting condition as resulted in aided by software Minitab-16 used is in ranged minimum limit with maximum of pre-study.

Table 5: Condition of Cutting Using Minitab-16 Software \begin{tabular}{l|l|l|l} 
Speed of Cutting (V) & $300 \mathrm{~m} / \mathrm{min}$ & $375 \mathrm{~m} / \mathrm{min}$ & $450 \mathrm{~m} / \mathrm{min}$
\end{tabular} \begin{tabular}{|l|l|l|l} 
Clear-cut (f) & $0.1 \mathrm{~mm} / \mathrm{rev}$ & $0.2 \mathrm{~mm} / \mathrm{rev}$ & $0.25 \mathrm{~mm} / \mathrm{rev}$ \\
\hline Speed of cutting (a) & $2.0 \mathrm{~mm}$ & $2.75 \mathrm{~mm}$ & $3.5 \mathrm{~mm}$
\end{tabular}

In order to optimum the plan on Figure 1 as above, there is done in treatment rate $\mathrm{R}_{\mathrm{a}}$ between $2.3 \div 12.6 \mu \mathrm{m}$ and $\mathrm{t}_{\mathrm{c}}$ between $5.6 \div$ $25.2 \mathrm{~min}$, aimed at approaching to probability price $(\mathrm{P})$ smaller or equal 0.05 . The results seen that rate $\left(R_{a}\right)$ there lies outside ranges rate $R_{a}$ of pre-study namely no series 26 and 27 with $R_{a}=13.1$ and $13.8 \mu \mathrm{m}$ is greater than the highest limit $R_{a}=12.6 \mu \mathrm{m}$ is greater than upper limit roughness surface of pre-study. Whereas the result treatment $t_{c}$ is still available on time ranged of time limit of cutting in pre-study between $5.6 \div 25.2 \mathrm{~min}$ or limit time of cutting as recommended ISO 3685 . This showed there is a closed correlation between condition of cutting to get rate of surface roughness and time of cutting. In order to have or approach price optimum of surface roughness $\left(\mathrm{R}_{\mathrm{a}}\right)$ and time of cutting $\left(\mathrm{t}_{\mathrm{c}}\right)$ on Figure 1, so parameter surface roughness and time of cutting must be determined prior as Table 6 .

Table 6L: Parameter Ra and tc \begin{tabular}{l|c|c|c|c|} 
Condition & Goal & Lowet Limit & Target & Upper Limit
\end{tabular} \begin{tabular}{|l|l|l|l|l|}
\hline Surface roughness $\left(\mathrm{R}_{\mathrm{a}}\right)$ & Maximum & $2.3 \mu \mathrm{m}$ & $5.6 \mu \mathrm{m}$ & $6.30 \mu \mathrm{m}$ \\
\hline
\end{tabular}

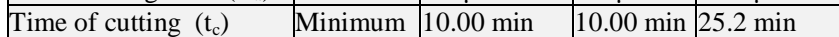
In order to get an optimal response (predicted) of surface roughness $\left(\mathrm{R}_{\mathrm{a}}\right)$ and time of cutting $\left(\mathrm{t}_{\mathrm{c}}\right)$ is done a data analysis in Figure 1 used Minitab-16 software aided. The results obtained such data of global settlement (variety cutting condition) and respond predicted (surface roughness rate) as Table 7,8 and 9, thence gained 27 varieties condition of cutting as provided on Figure 2.

Table 7: Starting Point

\begin{tabular}{|l|l|}
\hline \multicolumn{2}{|c|}{ Table 7: Starting Point } \\
\hline Clear-cut (f) & $300,0 \mathrm{~m} / \mathrm{min}$ \\
\hline Depth of Cutting (a) & $0.1 \mathrm{~mm} / \mathrm{rev}$ \\
\hline
\end{tabular}

Table 8: Global Settlement

\begin{tabular}{|l|l|}
\hline Speed of cutting (V) & $300,0 \mathrm{~m} / \mathrm{min}$ \\
\hline Clear-cut (f) & $0.15 \mathrm{~mm} / \mathrm{rev}$ \\
\hline Depth of cutting (a) & $2.0 \mathrm{~mm}$ \\
\hline
\end{tabular}

Table 9: Predicted Respond

\begin{tabular}{|l|l|l|l|}
\hline $\mathrm{R}_{\mathrm{a}}$ & $2.7 \mu \mathrm{m}$ & Desirability & 1.0 \\
\hline $\mathrm{t}_{\mathrm{c}}$ & 18.0 & Desirability & 1.0 \\
\hline
\end{tabular}

Composite Desirability $=1.00000$

Figure 1 showed that surface roughness prediction rate $\left(R_{a}\right)$ as resulted in optimum respond with the lowest rate $2.7 \mu \mathrm{m}$ and the highest $13.8 \mu \mathrm{m}$ has been outside the rate ranged of result treat- 
ment surface roughness $\left(R_{a}\right)$ namely $2.3 \mu \mathrm{m}$ lowest limit and 12.6 $\mu \mathrm{m}$ highest limit. This condition can be also consequence strongly interaction between variables of cutting condition.

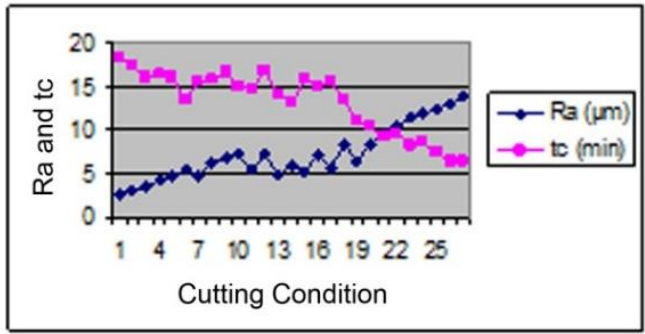

Figure 2: Graphic Condition of Cutting vs $\mathrm{R}_{\mathrm{a}}$ and $\mathrm{t}_{\mathrm{c}}$

The result of treatment in software Minitab-16 as Figure 1 is analyzed using a two-order equation so that resulted in an equation mathematics as the following.

The mathematics equation for surface roughness.

$R_{a}=49.2-0.379 V-51.9 f+8.44 a+0.000791 V^{2}+284 f^{2}-$ $2.84 a^{2}-0.124 V_{f}+0.0130 V_{a}+10.6 f_{a}$

The mathematics equation for time of cutting:

$t_{c}=52.7+0.592 \mathrm{~V}+232 f-117 a-0.00157 \mathrm{~V}^{2}-1837 f^{2}+$ $27.5 a^{2}+0.782 V_{f}+25.8 f_{a}$

Observing the result of calculation using a two-order equation as made in format Figure 3 showed that surface roughness $\left(t_{c}\right)$ order 20 and started adding its roughness up for the following time period, whereas the cutting time $\left(\mathrm{t}_{\mathrm{c}}\right)$ is upper in the starting of operation and go down means the time of cutting required go decreased down.

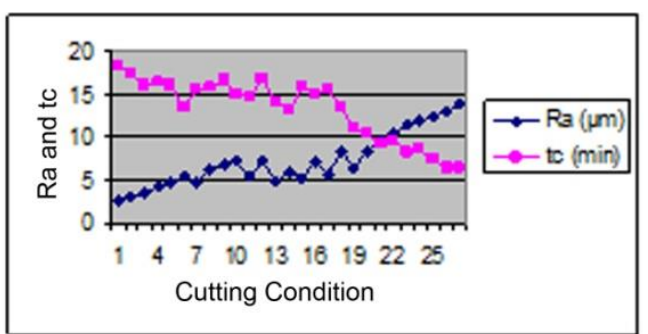

Figure 3: Graphic Condition of Cutting vs Calculation $R_{a}$ and $t_{c}$

Observing Figure 4 namely correlation between surface roughness $\left(R_{a}\right)$ compared a clear-cutting ( $f$ ) and speed of cutting $(V)$ is a form of surface as resulted variable condition of cutting accordance to Figure 2 with speed of cutting $(\mathrm{V})$ between $300 \div 450$ $\mathrm{m} / \mathrm{min}$, clear-cutting (f) $0.1 \div 0.25 \mathrm{~mm} / \mathrm{rev}$ and depth of cutting (a) $2 \div 3.5 \mathrm{~mm}$ that surface roughness as recommended started $<4$ $\mu \mathrm{m}$ lowest (the finest) is lied on the peak top and $>10 \mu \mathrm{m}$ is the greatest (the most roughness) is on bottom. The form of this surface divided into 8 levels started surface roughness between $9 \div$ $10 \mu \mathrm{m}$ moving shifted to $4 \div 5 \mu \mathrm{m}$, this data showed that clearcutting (f) is more dominant compared the depth of cutting (a) to the surface roughness. The form of surface as above also indicated that in essentially RSM cannot result any optimum point from a research operation and it can recommend only a location or points or optimum lines.

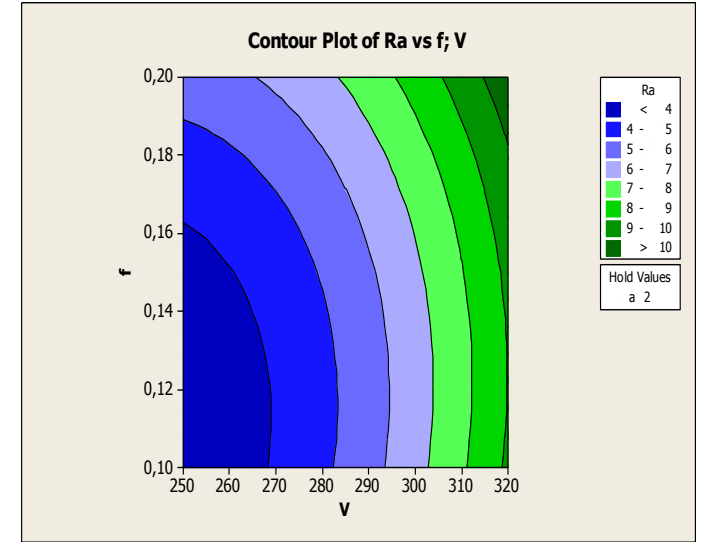

Figure 4: Form of Surface vs f and V

After made calculation using mathematics equation 1 and $2 \mathrm{ob}$ tained the result of surface roughness $\left(\mathrm{R}_{\mathrm{a}}\right)$ between $1.6 \div 6.3 \mu \mathrm{m}$ and ranges time of cutting $\left(\mathrm{t}_{\mathrm{c}}\right)$ between $10 \div 15$ minutes for a condition finish medium machining determined in 3 variables condition of cutting fulfilling qualification to make into condition of optimum cutting as Table 10 as below.

Table 10: Condition of Optimum Cutting vs Ra and $t_{c}$

\begin{tabular}{|c|c|c|c|c|}
\hline $\mathbf{V}(\mathbf{m} / \mathbf{m i n})$ & $\mathbf{f}(\mathbf{m m} / \mathbf{r e v})$ & $\mathbf{a}(\mathbf{m m})$ & $\mathbf{R}_{\mathbf{a}}(\boldsymbol{\mu m})$ & $\mathbf{t}_{\mathbf{c}}(\mathbf{m i n})$ \\
\hline 300 & 0.15 & 2.0 & 5.4 & 13.4 \\
\hline 449.9 & 0.17 & 2.2 & 5.6 & 14.7 \\
\hline 353.4 & 0.15 & 2.0 & 4.8 & 14.1 \\
\hline
\end{tabular}

Figure 2 is a graphic displaying comparison of gained surface roughness $\left(\mathrm{R}_{\mathrm{a}}\right)$ averagely between the result of calculation to experiment on dry condition cutting and by 3 points optimum surface roughness $\left(\mathrm{R}_{\mathrm{a}}\right)$ as above indicated that surface roughness rate of experiment is lower compared the result of calculation. As seen again to Figure 2 (the result of analysis of Minitab-16 software) there is a closed correlation between variety condition of cutting $(\mathrm{V}, \mathrm{f}$ and $\mathrm{a})$ to the cutting time and surface roughness of machining, extended time of cutting achievable by chisel (refers ISO 3685 ), the results is tending to produce a lower surface roughness.

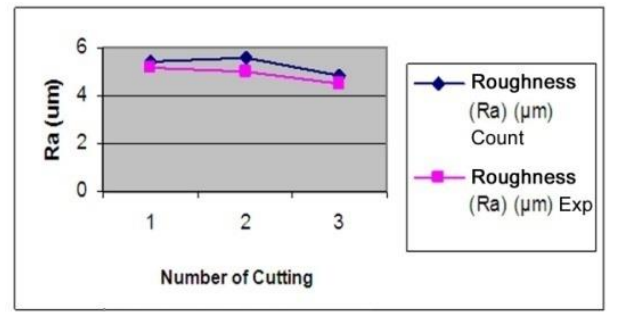

Figure 5: Graphic Roughness of Dry Surface

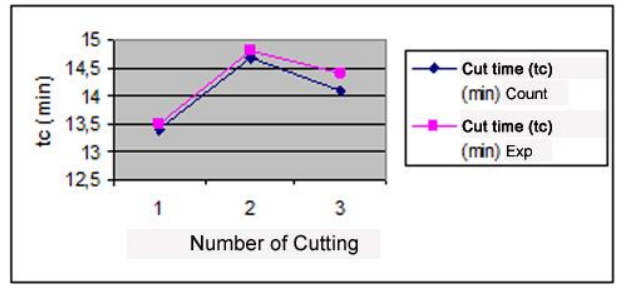

Figure 6: Graphic Time of Dry Cutting

The result of experiment on wet machining as of 3 conditions of optimum cutting order 1 through 3 resulted in average surface roughness $\left(\mathrm{R}_{\mathrm{a}}\right)$ is better $=5.5$ compared the result of surface roughness of calculation $=5.8 \mu \mathrm{m}$ found $=0.3 \mu \mathrm{m}$ whereas the time of cutting $\left(\mathrm{t}_{\mathrm{c}}\right)$ averagely indicated that the result of calculation is shorter namely $=13.6 \mathrm{~min}$ compared the result of experiment with time $=14.7 \mathrm{~min}$ about $1.1 \mathrm{~min}$. The difference in surface roughness rate $\left(R_{a}\right)$ and time of cutting $\left(t_{c}\right)$ result of experiment on dry optimum cutting condition with wet is $0.15 \mu \mathrm{m}$ and $1.14 \mathrm{~min}$. This existence indicated that cutting gained not produce a significant difference on surface roughness $\left(R_{a}\right)$ and time of 
cutting $\left(\mathrm{t}_{\mathrm{c}}\right)$. Seen Figure 5, 6, 7 and 8 showed that surface roughness rate $\left(R_{a}\right)$ averagely there is no significant difference between the result of calculation with experiment on dry and wet condition done, whereas on time of cutting $\left(\mathrm{t}_{\mathrm{c}}\right)$ found additional time of cutting average $7.76 \%$. This indicated that machining operation on wet condition not influenced more compared to dry condition (use no fluid of cutting) to the surface roughness rate of machining.

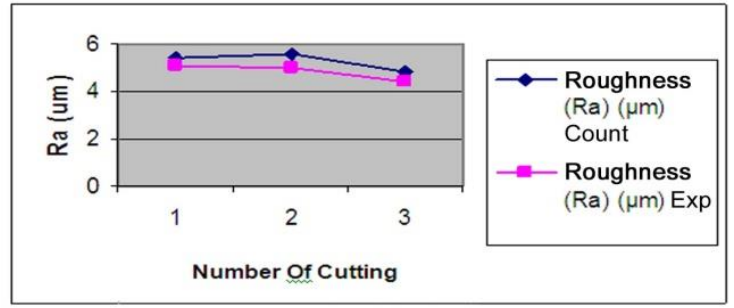

Figure 7: Graphic Wet Surface Roughness

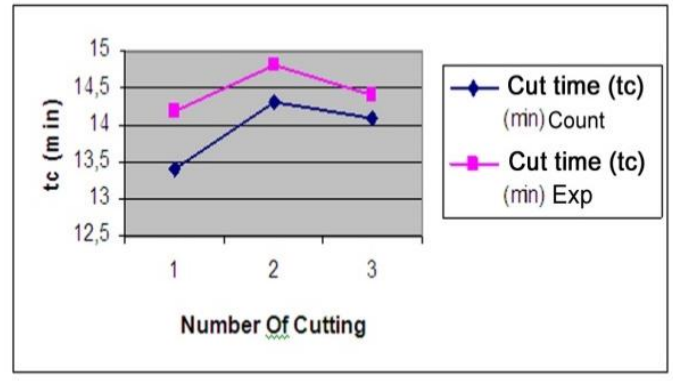

Figure 8: Graphic Wet Cutting Time

In order to know whether the result of cutting on dry condition has significant difference on the cutting on wet condition is analyzed using a statistic test $t$ due data population is still below 30 (Walpole and Reymond, 1996). By Figure 5 and 6, obtained rate $\overline{x_{1}}=$ $3.17 \%, \mathrm{n}_{1}=4, \overline{x_{2}}=3.32$ and $\mathrm{n}_{2}=3$ then can calculate using formula below.

$$
\begin{aligned}
\left(\mathrm{S}_{1}\right)^{2} & =\frac{\sum\left(x_{i}-\bar{x}\right)^{2}}{n-1} \\
\left(\mathrm{~S}_{2}\right)^{2} & =\frac{\sum\left(x_{i}-\bar{x}\right)^{2}}{n-1} \\
(\mathrm{Sp})^{2} & =\frac{\left(n_{1}-1\right) S_{1}^{2}+\left(n_{2}-1\right) S_{2}^{2}}{\left(n_{1}+n_{2}\right)-2}
\end{aligned}
$$

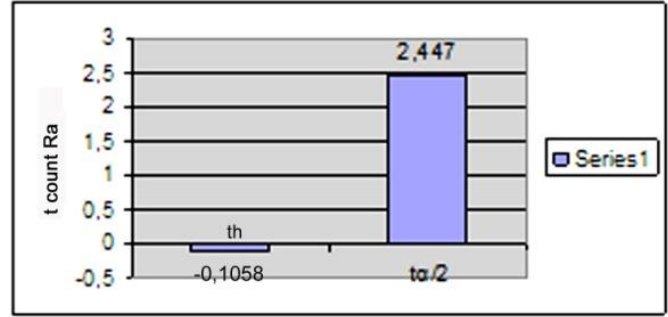

Figure 9: Graphic of Significance Surface Roughness $\left(\mathrm{R}_{\mathrm{a}}\right)$

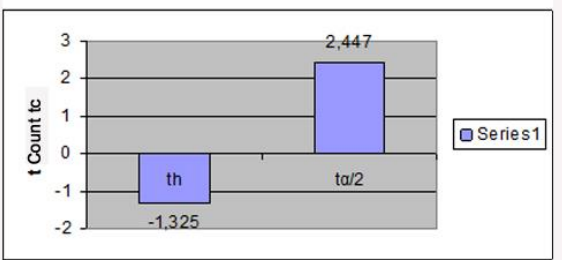

Figure 10: Graphic of Significance Time of Cutting $\left(\mathrm{t}_{\mathrm{c}}\right)$
Refers to the result of statistical analysis on surface roughness rate $\left(\mathrm{R}_{\mathrm{a}}\right)$ and time of cutting $\left(\mathrm{t}_{\mathrm{c}}\right)$ on optimum dry condition and wet condition make a significant difference, if viewed from machining process side this present alternative option on dry machining to apply on IKM businessmen of machining many handle processing carbonate steel material. If viewed from economics point that without any fluid of cutting truly is going to run down ranges $16 \div$ $20 \%$ of production cost as presented by Sreejith and Ngoi (2000) in paper. This however indicated that dry machining of carbonate steel able to improve productivity on medium machining rate refers to standard ISO 3685 .

\section{Conclusion}

By analysis, data presented and discussion as previously mentioned, it can conclude that as followings:

a. The Respond Surface Method (RSM) is successful applied on the dry optimum cutting to carbonate steel $\mathrm{VCN}-150$ on the cutting condition $\mathrm{V}=300 \mathrm{~m} / \mathrm{min}, \mathrm{f}=0.15 \mathrm{~mm} / \mathrm{rev}$ and $\mathrm{a}=2.0$ $\mathrm{mm}$ the result $\mathrm{R}_{\mathrm{a}}=5.4 \mu \mathrm{m}$ and $\mathrm{t}_{\mathrm{c}}=13.4 \mathrm{~min}$, the cutting condition $\mathrm{V}=449.9 \mathrm{~m} / \mathrm{min}, \mathrm{f}=0.17 \mathrm{~mm} / \mathrm{rev}$ and $\mathrm{a}=2.2 \mathrm{~mm}$ with result $\mathrm{R}_{\mathrm{a}}=5.6 \mu \mathrm{m}$ and $\mathrm{t}_{\mathrm{c}}=14.7 \mathrm{~min}$, the cutting condition $\mathrm{V}$ $=353.4 \mathrm{~m} / \mathrm{min}, \mathrm{f}=0.15 \mathrm{~mm} / \mathrm{rev}$ and $\mathrm{a}=2.0 \mathrm{~mm}$ with the result $\mathrm{R}_{\mathrm{a}}=4.8 \mu \mathrm{m}$ and $\mathrm{t}_{\mathrm{c}}=14.1 \mathrm{~min}$.

b. There is no found significant differences between dry machining to wet on optimum cutting condition of dry $\mathrm{V}=300$ $\mathrm{m} / \mathrm{min}, \mathrm{f}=0.15 \mathrm{~mm} / \mathrm{rev}$ and $\mathrm{a}=2.0 \mathrm{~mm}$ with result $\mathrm{R}_{\mathrm{a}}=5.4$ $\mu \mathrm{m}$ (dry) $\mathrm{R}_{\mathrm{a}}=5.1 \mu \mathrm{m}$ (wet) and $\mathrm{t}_{\mathrm{c}}=13.4 \mathrm{~min}$ (dry) $\mathrm{t}_{\mathrm{c}}=14.7$ min (wet), optimum cutting condition of dry $V=449.9 \mathrm{~m} / \mathrm{min}$, $\mathrm{f}=0.17 \mathrm{~mm} / \mathrm{rev}$ and $\mathrm{a}=2.2 \mathrm{~mm}$ with results $\mathrm{R}_{\mathrm{a}}=5.6 \mu \mathrm{m}$ (dry) $\mathrm{R}_{\mathrm{a}}=5.2 \mu \mathrm{m}$ (wet) and $\mathrm{t}_{\mathrm{c}}=14.7 \mathrm{~min}\left(\right.$ dry) $\mathrm{t}_{\mathrm{c}}=14.9 \mathrm{~min}$ (wet), an optimum cutting condition of dry cutting $\mathrm{V}=353.4$ $\mathrm{m} / \mathrm{min}, \mathrm{f}=0.15 \mathrm{~mm} / \mathrm{rev}$ and $\mathrm{a}=2.0 \mathrm{~mm}$ results $\mathrm{R}_{\mathrm{a}}=4.8 \mu \mathrm{m}$ (dry) $\mathrm{R}_{\mathrm{a}}=5.7 \mu \mathrm{m}$ (wet) and $\mathrm{t}_{\mathrm{c}}=14.8 \mathrm{~min}$ (wet).

c. It is proved by an statistical analysis with results $t_{h}=-0.1058$ $<t_{\alpha / 2}=(2.447)$ so $H_{0}$ is acceptable means there is no significant differences of surface roughness $\left(\mathrm{R}_{\mathrm{a}}\right)$ between the dry cutting condition to the wet cutting condition. On the time of cutting as $t_{h}=-1.3250<t_{\alpha / 2}=(2.447)$ so $H_{0}$ is acceptable means there is no significant difference of time cutting $\left(\mathrm{t}_{\mathrm{c}}\right)$ between dry cutting condition with the wet cutting condition.

d. The machining with carbonate steel using carbide chisel can be implemented and recommended to those IKM-small industries in Medan and surroundings.

e. At the end of study indicated that dry machining is highly potential used if viewed from age aspect of chisel and packaging of machining' surface.

\section{References}

[1] A. Hasibuan et al., "Performance analysis of Supply Chain Management with Supply Chain Operation reference model," vol. 1007, pp. 1-8, 2018.

[2] O. K. Sulaiman et al., "Bellman Ford algorithm-in RoutingInformation Protocol ( RIP )," vol. 1007, pp. 1-9, 2018.

[3] A. A. Noordin, M.Y., V.C. Venkatesh, S. Sharif, S. Elting, "Application of Response Surface Methodology in describing the Performance of Coated Carbide Tools when Turning AISI 1045 Steel," J. Mater. Process. Technol., 2004.

[4] C. Haroen, G. A, and G. JH, The Influences of tool wear and Tool Life on Surface Integrity During Turning Tool Steel Using Uncoated Carbide. 2000.

[5] R. E. R. H. M. Walpole, Ilmu Peluang dan Statistika untuk Insinyur dan Ilmuan, 4th ed. Bandung: ITB, 1996.

[6] B. Wassila, "Catting Parameter Optimization to Minimize Production Time In High Speed Turning," J. Mater. Process. Technol., 2004

[7] K. Schintlmeister, W, Wallgram, Wkanz, J.\& Gigl, Cutting Tool Materials Coated by Chemical Vavour Deposition. 1984.

[8] N. B. Sreejith, P.S, Dry Machining: Machining of the Future. School of Machanical and Production Engineering. Nanyang Technology University Singapure, 2000. 
[9] T. Rochim, Teori \& Teknologi Proses Permesinan. Higher Education Development Support Project. Jakarta, 1993.

[10] S. Y. M. A. R, "Surface Roughnees Model For Machining Mild Steel With Coated Carbida Tool," Mater. Des., vol. 26, no. 4, pp. 321-326, 2008.

[11] MTA-MSE, No TitleThe Manufacture of Machining Technology And Process Machining Technology Assoc. of The Soc Manufacture Engineering. 2001.

[12] A. Ginting, "Tool Wear, Tool Life and Surface Roughness Evaluation in High Speed Machining of Tool Steel with Multilayer Ceramic CVD-Coated Carbide Tool," J. Ist. Mater. Malaysia, vol. 2, no. $1,2001$.

[13] D. C. Monggomery, Design and Analiysis of Experiment, 4th ed. Jhon Wiley \& Sons Inc., 1997.

[14] J. I. N. Ashvin J. Makadia, Optimation of Machining Parameters for Turning Operation Basedon Respone Surface Methodology. India: Gujarat Technology University, 2013. 